\title{
Geotechnical Aspects of Sub-Sea Tunnelling on the Musaimeer Pumping Station and Outfall Tunnel Project
}

\author{
Gary Peach \\ gary.peach@mottmac.com \\ Mott MacDonald, Doha, Qatar \\ Mirjana Hrnjak \\ mirjana.hrnjak@mottmac.com \\ Mott MacDonald, Doha, Qatar \\ Ioannis Papadatos \\ Ioannis.papadatos@auccqatar.com \\ HBK-PORR JV, Doha, Qatar \\ Hernan Vigil \\ hernan.vigil@auccqatar.com \\ HBK-PORR JV, Doha, Qatar
}

\begin{abstract}
Musaimeer outfall tunnel is one of the longest storm water tunnels in the world with a total length of $10.2 \mathrm{~km}$. The tunnel is connected via a drop shaft to the main pump station. This system will accommodate surface and storm water received from the drainage networks of $270 \mathrm{~km} 2$ of urban areas in southern Doha. Though the geological conditions remain similar to those in Qatar Metro projects, in this project, the tunneling faced new challenges because the outfall tunnel alignment is $40 \mathrm{~m}$ deep $(25 \mathrm{~m}$ below the water of Gulf plus $15 \mathrm{~m}$ under the seabed). This project involves the construction of the outfall tunnel with an internal diameter of $3700 \mathrm{~mm}$ sloped at $0.05 \%$ upward to the riser shaft. The riser shaft, which is located at the end of the outfall tunnel, is connected to a diffuser field located on the seabed. The tunnel will be excavated by Tunnel Boring Machine (TBM) and is expected to encounter possible water inflows at high pressure, complex mixed ground, weaker ground strata prone to cavities or voids and the presence of vertical and lateral fractures connected to the seabed. The geotechnical parameters in sub-sea tunnelling are being assessed through all main project stages; a) Evaluation b) Verification and c) Application during the execution of this project which is currently in progress. The tunnel alignment traverses through the Rus formation, Midra shale and Simsima Limestone. The TBM will require periodic atmospheric or hyperbaric interventions at the cutter head for cutter tool maintenance. During this process, the face can be mapped and compared to off-shore borehole logs. Geophysical seismic reflection/refraction and resistivity surveys have been carried out along the tunnel alignment. A non-intrusive radar system facility, installed on the TBM cutter-head, able to probe ahead in real time the ground conditions is also presented. By looking at TBM excavation parameters such as, thrust force, torque, penetration, cutter head rotation speed, correlations can be made to the above surveys and a look ahead plan can be developed to aid TBM operation.
\end{abstract}

Keywords: TBM; Sub-sea tunnel; Hydrostatic pressure; Offshore geophysics; Nonintrusive radar system; Face mapping; TBM parameters 


\section{INTRODUCTION}

The Musaimeer Pumping Station project is governed by the Qatar Construction Specifications (QCS, 2014). The Public Works Authority (PWA) have engaged in two contracts. Firstly Mott MacDonald Ltd., which is the Project Management Consultant (PMC) company, and HBK-PORR JV, which is the Design, Build, Operation and Maintain Contractor for the construction of the MPSO Project, which is the final receiver of the upstream drainage system and located at the end of the Abu Hamour Tunnel, immediately south of the Hamad International Airport (HIA). The outfall tunnel is extending from the pump station, $10 \mathrm{~km}$ off-shore discharging drainage system flows into the Gulf. The discharging will be performed through a vertical riser shaft and a marine outfall diffuser field. Figure 1 shows the project location.

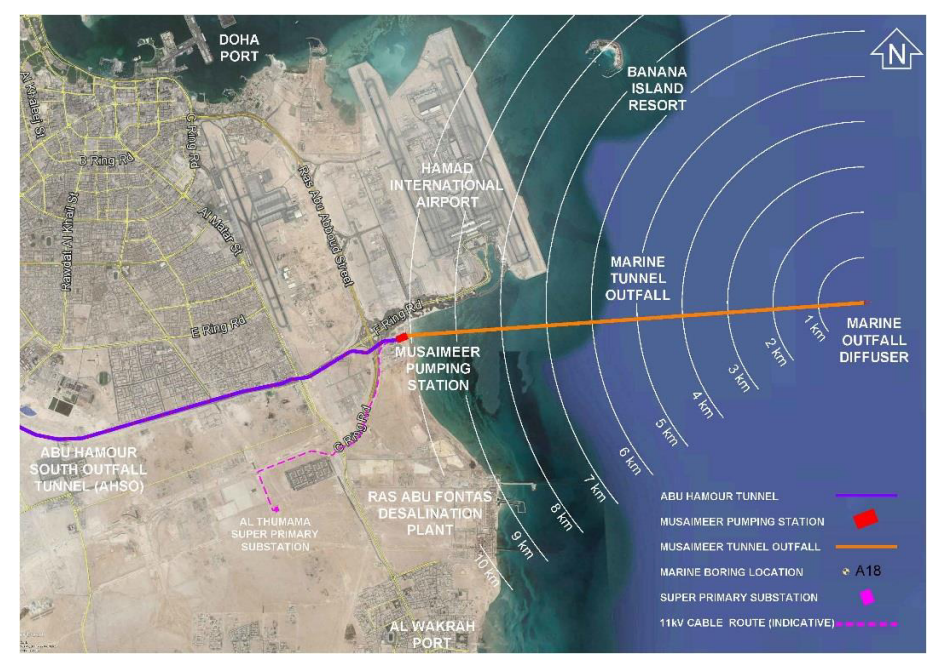

Figure 1: Project Location

\section{TENDER GEOTECHNICAL INVESTIGATION - EVALUATION STAGE}

PWA (Ashghal) undertook a significant geotechnical investigation program for this particular project prior to tender stage, which consisted of drilling 22 offshore boreholes at $500 \mathrm{~m}$ centers, which provided the following geotechnical data:

1. Cores for inspection.

2. In-situ packer tests.

3. Pressure meter tests at each location.

4. Geophysical surveys Sonar Bathymetry,Magnetometer, Seismic Reflection and Seismic Refraction.

5. Laboratory mechanical and chemical tests on soil, rock and water samples.

This geotechnical factual data was available during the early project stage based on which the Contractor made the initial assessment and evaluation of the foreseen tunnel geotechnical conditions. The factual investigation data was combined on a long geotechnical profile which became the basis of the outfall tunnel project, in terms of selection of the TBM machine and tunnel segmental lining, assess the tunnel construction baseline program, evaluate all the tunneling risks and the mitigation measures. Figure 2 shows the long geological profile. 


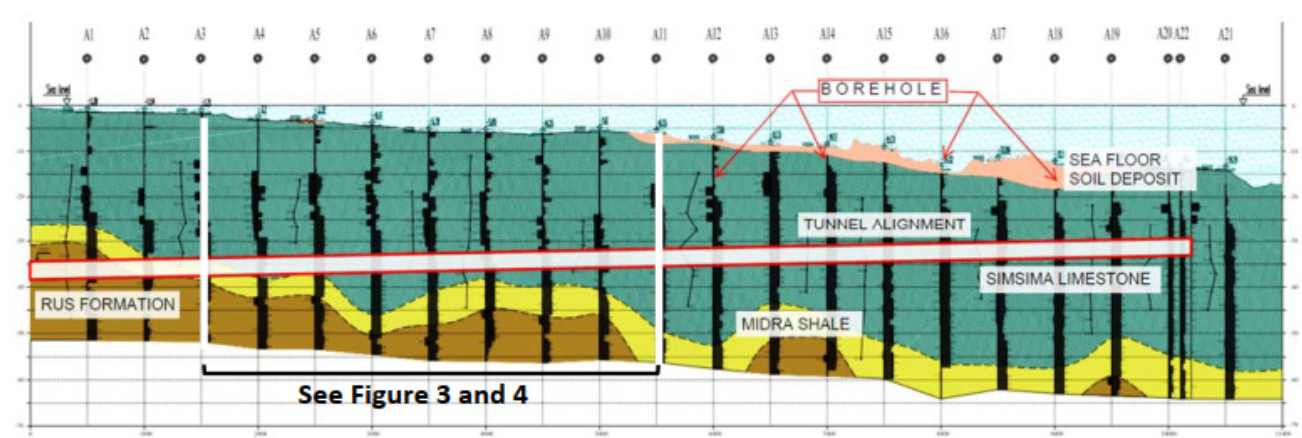

OUTFALL TUNNEL GEOTECHNICAL SECTION

Figure 2: Outfall tunnel geotechnical section

The evaluation of the geotechnical factual data was also a challenge, due to the subsea nature of the tunnel. Although there was a significant experience in TBM tunneling in the Doha area, there was no previous experience on subsea tunneling on the area. The above data indicated the rock quality to be fairly competent along the tunnel alignment, however, there were two major tunnelling risks which required mitigation by the Designer and Contractor. Witnin Figure 2 above are references to two other Figures namely 3 and 4 .

\subsection{Karstic Features}

The first risk the TBM could encounter is karstic features along the tunnel alignment. Although the tender geotechnical investigation has shown no evidence of karstification on the calcareous formations of Rus, Midra and Simsima. However, the risk was still valid. The size of a potential kasrtic feature was also very important and the mitigation possible measures limited, considering that the accessing and intervention from top due to the sea presence was an almost impossible operation. The TBM was desinged and equipted with grouting ports ahead and around the sheild and associated drilling facility, to mitigate this potential hazard which could impede the advancing of the tunnel.

\subsection{Hydraulic Connection to Seabed}

The second high risk was associated with the hydraulic connection between the seabed and the TBM tunnel. In this case the full hydraulic water pressure, would be directed to the advancing TBM cutterhead, requiring to increase the face pressure and thrust accordingly to balance and advance the tunnel. To mitigate this risk, the TBM was designed to withstand the full hydraulic pressure. However there were significant factual evidences based on the existing geotechnical investigation that along the $85 \%$ of tunnel total stretch, competent and low permeability rock would be encountered by the TBM, and at least one tunnel diameter above tunnel crown, providing a safe cover against water infiltration from above. This assessment was based on RQD (Rock Quality Designation) records and the Lugeon field tests performed in the offshore boreholes. Only $15 \%$ of the tunnel alignment was rock of poorer quality with increased permeability based on lugeon tests. 


\section{TUNNEL BORING MACHINED (TBM) SELECTION}

The TBM selected took into consideration the requirements of BS 6164:2011 to excavate the the tunnel and was an Earth Pressure Balance (EPB) designed to support a maximum face working pressure of 4.5 bar on the bulkhead to support the maximum working pressure (full hydrostatic) which has been estimated between 0 and 4 Bar. The TBM selcted Typical EPB configuration has a cutterhead, excavation chamber, main bearing or drive, screw conveyor, front, middle and tail shields, man looks, thrust system, articulation, erector and brushes as part of the tail shield seal system. In addition, there are 18 gantries (160 m allocating all electro mechanical parts, additive tanks and rescue chambers among other requirements).

The most important modifications required in this TBM is related to minimize or eliminate the risk uncontrolled water inflow into the tunnel during construction. To prevent this water inflow from the chamber, the TBM has two set of gates, one is located at the end of the screw (double gate) that is being used during normal operation and able to close automatically in case of power shout down. In the event of extraordinary difficult geological conditions like over size voids, the TBM has the facilities to perform drilling for explorations and grouting through the shields by using preventers. The remining set of gates called "guillotine gates" is allocated between screw conveyor and bulkhead and this is considered the final option to be used in case of the gates at the screw conveyor fail.

\section{POST TENDER GEOTECHNICAL INVESTIGATION.}

The contract requirements specified the implementation of an additional 24 offshore boreholes. However, it was considered that in terms karst identification and possible hydraulic connection to the sea, the drilling of small diameter investigation boreholes would provide minimal benefit to the TBM operation. The drilling of small diameter investigation marine boreholes would only provide additional pin marks on the map, but not a richer picture of the overall hydrogeological and structural conditions along tunnel alignment.

The Contractor has decided to invest on a detailed geophysical investigation survey as a more beneficial approach to mitigate the major geotechnical risks and provided more complete geotechnical information regarding variations in geology, areas of seawater saturation, areas of cavities, weak disturbed zones or other discontinuities under the seabed between the existing 22 boreholes. Thus this geophysical survey was proposed and accepted by the Client.

With the use of a marine geophysical method, it might be possible to get an overall picture of the underground conditions, indicate some critical tunneling areas, schedule the required tunnel interventions and reduce the tunneling risk level further, regarding geotechnical unforeseen hazards.

Based on the above two different types of detail offshore geophysical surveys have been conducted along the outfall tunnel alignment, The Electrical Resistivity Tomography (ERT) and the Seismic Reflection Geophysical Tomography.

\subsection{Electrical Resistivity Tomography Survey (ERT)}

The objective of Electrical Resistivity Tomography (ERT) is to determine the 
subsurface distribution in two or three dimensions (2D and 3D) of resistivity, a physical parameter of the earth that is related to key geological parameters such as soil or rock type and mineral content, as well as the porosity and degree of water saturation in the rock. This ERT survey was performed satisfactorily in good weather conditions and the successive data were processed, analyzed and interpreted. The survey covered more than $10 \mathrm{~km}$ of triple parallel ERT marine profiles, aligned along the tunneling corridor (West to East), at $3 \mathrm{~m}$ distances between them, integrated by a total of sixteen transversal ERT marine profiles distributed in a crossing direction (South to North) along the $10 \mathrm{~km}$ West-East survey tunnelling orientation.

After coducting the offshore survey, the most accurate possible electrostratigraphic model has been developed and refined on the final phase of study and the possible correlation between resistivity value variations and the main three different geologic units have been identified. A number of "conductive anomalies" and "resistive anomalies" have been detected along ERT profiles and documented accordingly. Figure 3 is an extracted section from the whole tunnel survey.

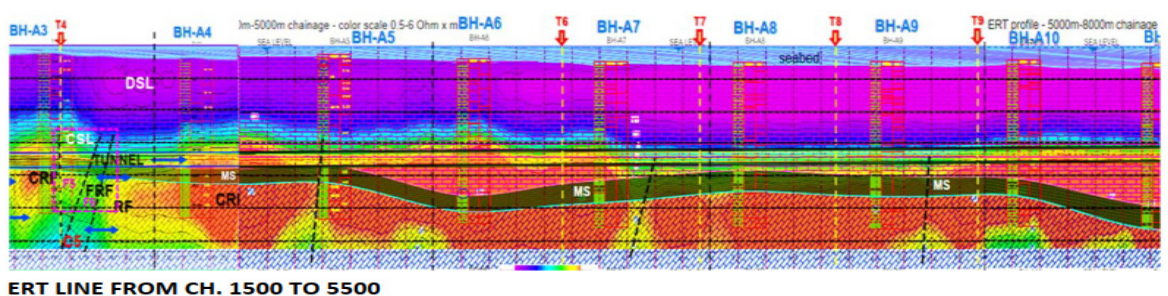

Figure 3: ERT line from $0+200$ to $2+200$

\subsection{Seismic Reflection Geophysical Survey}

This process consists of recording the acoustic waves generated at the surface which are reflected by sub-surface structures or interfaces. A reflection will occur when the density and/or the velocity changes at the boundary between two different materials. The acoustic waves are recorded from numerous hydrophones, installed at fixed distance along a seismic cable (streamer).

The seismic reflection geophysical survey is used to correlate the existing borehole defined stratigraphy, confirm the extend of topsoil formations and identified possible vertical weak zones, that may result in excessive water ingress along the TBM tunnel drive. Figure 4 shows a typical section of this survey.

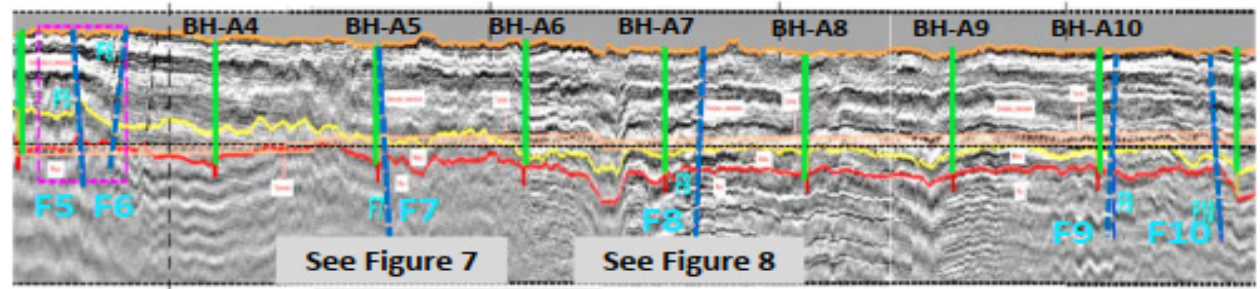

SEISMIC REFLECTION PROFILE FROM CH. 1500 TO 5500

Figure 4: Seismic Reflection Profile 
Based on the interpretation of Seismic Reflection Long and Cross Sections certain structural vertical zones/faults were identified indicating possibilities of increased water ingress, these features are marked F5 to F10 and are points on the survey where abrupt changes in the sesismic wave received profiles. Durring this assessment 20 such zones were identified, and thus planning can be instigated to withstand possible full hydrostaic water pressure.

\section{FORESEEN GEOTECHNICAL CONDITIONS ALONG THE TUNNEL}

To plan ahead and anticipate different ground conditions and hence assess programme impacts on the TBM operation the pretender and additional geotechnical information are combined according to the tunnel chainage. In order to ensure the TBM advances smoothly the cutterhead requires regular inspection, maintenance and repair. The most efficient way to carry this out is in ground conditions which are safe under atmospheric conditions. This operation becomes more complex and time consuming in poorer ground conditions which require hyperbaric support, performed in accordance with Compressd Air regulations (1996/1656). Thus to mitigate the impact of various ground conditions an assessment is made by linear meter of the likelihood of favorable sections where only atmospheric interventions are anticipated, i.e., on Moderate sections where atmospheric interventions are anticipated but hyperbaric may also be required and on Unfavorable sections where TBM interventions should be avoided, unless absolutely required. If required then hyperbaric conditions should be applied. Figure 5 illustrates a typical section of the Foreseen geotechnical profile. The favourable, moderate and unfavourable zones are color coded accordingly.

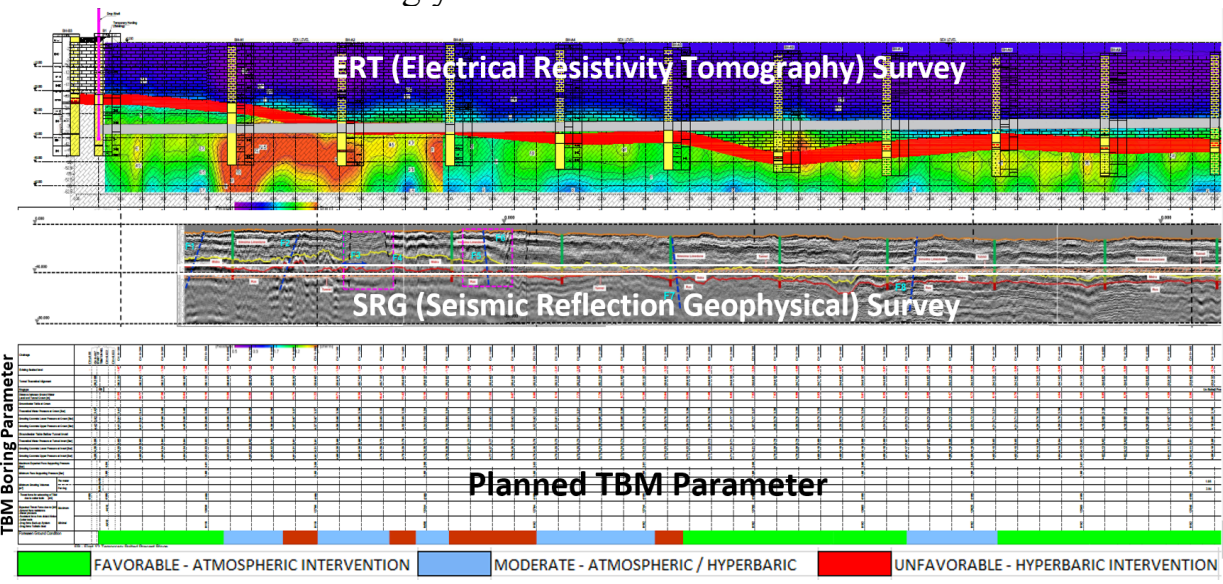

Figure 5: Foreseen geotechnical conditions profile

\section{REAL TIME NON-DESTRUCTIVE RADAR STEM (Beam System)}

The TBM is provided with a non-intrusive electrical induced polarization prediction system able to provide predictions of the ground conditions and interpretations up to three tunnel diameters ahead and about $3 / 2$ of the tunnel diameter in real time. The Bore-tunneling Electrical Ahead Monitoring (BEAM) System is based on a geotechnical principle that rock mass has different resistivity at varying frequencies, expressed with the Percentage Frequency Effect (PFE). The information is displayed in a matrix, which 
combines both resistivity and PFE.

The interpretation of the matrix, which is shown in Figure 6, is based on the columns and rows; factors on the columns refer to the karst interpretation (P1:P4) while factor on the rows $(\mathrm{R} 3: \mathrm{R} 1)$ refer to the possibility of water inflow. There is a computer located in the TBM operators' cabin where the information and interpretation are shown on real time as the TBM moves forward, the TBM operator can monitor and correlate with other parameters.

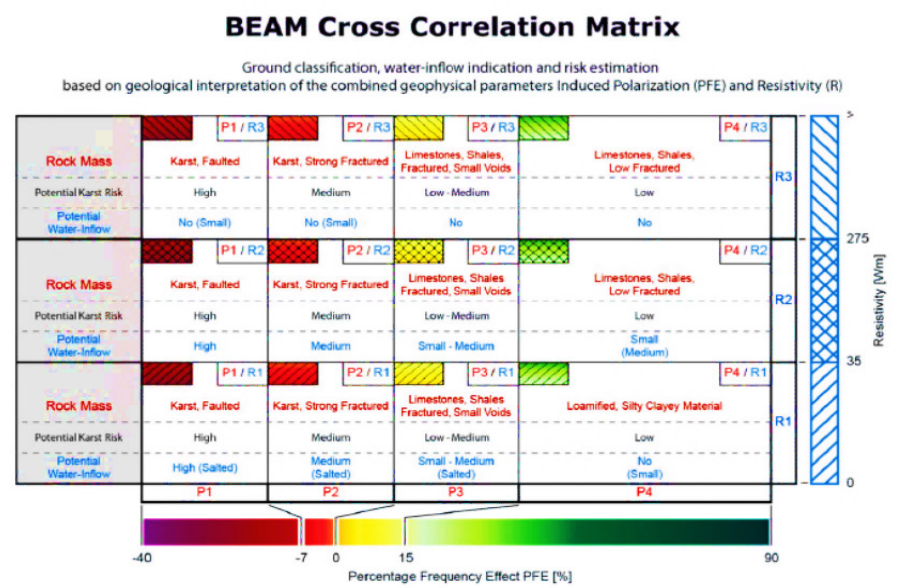

Figure 6: Beam Matrix

Figure 7 shows the real time Beam display, the TBM passing through an area in which the rocks mass is limestone, fracture with small voids, potential karst risk is lowmedium and potential aquifer risk is small-medium.
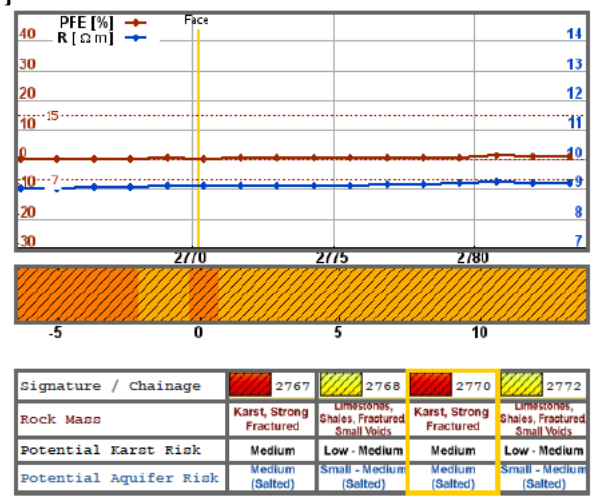

Figure 7: Beam Display

However, in Figure 8 the TBM is shown tunneling in a rock mass with higher potential risk of karts and aquifer, this particular location referes to a previously indentified fault F7. The interpretation coming out from the matrix must be compared with some specific parameters in the TBM, like torque, thrust force, penetration rates, advance speed and cutterhead rotation speed among others. 


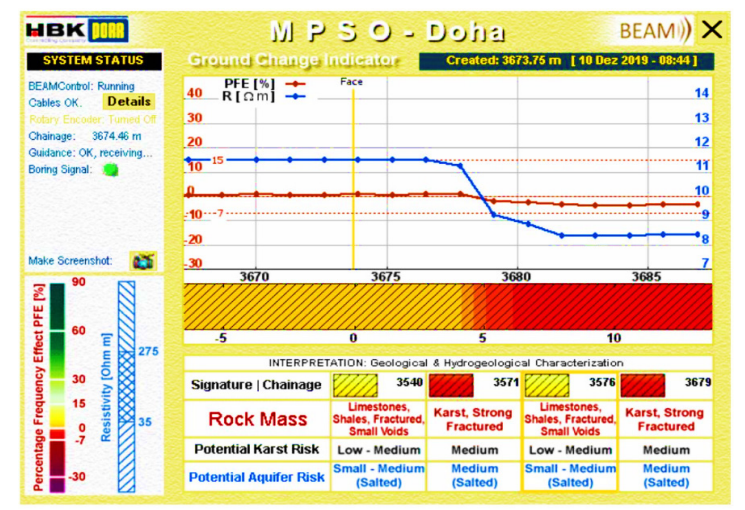

Figure 8: Beam Display for F7

It is important to note that there are limitations on the precision accuracy of the system. The system is not able to identify whether the TBM is passing through Rus formation, Midra Shale or Simsima limestone, it can only identify intrinsic properties of rock mass. It is not also possible to measure the exact amount of water inflow and location. The system can provide an estimation of the possibility that water inflow or aquifers might be encountered. The system can show fractures and cavities that are not found during tunneling because the volume of the tunnel measure is $3 / 2$ of the tunnel volume.

\section{TBM PROGRESS TO DATE}

TBM tunneling operations commenced February 2019, have encountered so far as foreseen, $1 \mathrm{~km}$ of Rus formation, then $0.8 \mathrm{~km}$ of Midra Shale formation and $2.0 \mathrm{~km}$ of Simsima Limestone, which is expected to continue until the tunnel is completed and reaches the riser shaft. The transition zones between the formation of the tunnel crosses through mixed geological conditions between Rus formation and Midra shale have been characterized by the absence of ground water and presence of limestone bands with gypsum lenses and calcite veins. Those geotechnical factors found along Midra shale constrained the performance of the TBM in terms of advance rates. The torque of the TBM increased up to $75 \%$ of its nominal capacity, the penetration rates were very low around 4 to $5 \mathrm{~mm}$ per rpm, the injection of water in the excavation chamber reached $20 \mathrm{~m} 3$ per ring and parameters related to foam FIR, FER and CF were duplicated and sometimes triplicated to reach an acceptable soil conditioning. However, it was not possible to avoid scenarios of clogging in the cutter-head and several damages on the cutting tools which required a high number of cutter-head interventions in atmospheric conditions. Logistics in the tunnel were tremendously affected, that required a reconfiguration of the trains regarding the number of skips required to dispose the solid due to higher swelling value. The installation of the California switch was anticipated to reduce the idle TBM time during train changing. The encountered geological fracture zones F7 and F8, forced the TBM to operate in full hydrostatics pressure from 3.4 to 3.8 bar, reducing the advance rates.

In both cases, geotechnical engineers and TBM team were monitoring and correlating 
the geotechnical profile and BEAM system profiles to adjust and optimize the performance of the TBM via drive instructions.

\section{CONCLUSION}

As tunneling work is considered as a highly challenging project, because it is constructed in subsea conditions, has a small inner diameter $(3700 \mathrm{~mm})$, a very long length $(10,200 \mathrm{~m})$ and has no intermediate access points. The need for comprehensive, accurate and in-depth geotechnical information is critical to a successful tunnel completion. There is no single advance ground investigation method that can completely predict the ground conditions in front of a TBM. There are however several systems that can give an insight into a aspect of the geological conditions that lie in front of the TBM. When the results of these methods are integrated, the prediction can be comprehensive.

On this project, the key issue was the cross correlation with other methods and observed geology in a standard format which allows the identification of patterns and trends. This may well be unique to this project.

\section{REFERENCES}

Qatar Construction Specifications (QCS) (2014). Revision IV.

Public Works Authority (2017). Professional Services Agreement for Professional Consultancy Services - Post Contract Professional Consultancy Services, Project CP 671/2, Musaimeer Pumping Station and Outfall, Project ID: IA 2016 S 005 G, Contract Number: P2017/22. www.ashghal.gov.qa

Public Works Authority (2017). Contract Documents for Design, Build, Operate and Maintain of Musaimeer Pumping Station and Outfall, PROJECT ID: IA 14/15 C 015 G, Contract Number: C2017/109.www.ashghal.gov.qa

The British Standards Institution (2011). BS 6164:2011 Code of practice for health and safety in tunnelling in the Construction industry, BSI Standards Publication, London.www.bsigroup. com

Health and Safety Executive (UK) (1996). A guide to work in the Compressed Air Regulations (SI 1996/1656). www.hse.gov.uk 